\title{
Modeling the Purpose for Renting Passenger Vehicles
}

Terence Dimatulac, Hanna Maoh ${ }^{\dagger}$, Shakil Khan ${ }^{\ddagger}$

Keywords: canada, multinomial logit model, choice behavior, rental vehicles

https://doi.org/10.32866/10937

\section{Transport Findings}

\begin{abstract}
This article specifies and estimates a multinomial logit model (MNL) to explain the purpose of renting a vehicle for short-term use. The model, which predicts the probability of renting a vehicle for business, leisure, temporary replacement, or other purposes, is estimated using a random sample of approximately 1,000 individuals from 10 Canadian provinces. The records used in the analysis were collected in 2016 via an online survey. The findings suggest that the purpose for renting could be predicted through factors associated with the sociodemographic characteristics of the renters and their rental plans, as well as attributes associated with the rented vehicle.
\end{abstract}

\section{RESEARCH QUESTION AND HYPOTHESES}

The majority of commercial vehicle fleets in Canada are owned by rental companies (Canadian Automotive Fleet 2019). Despite the noticeable demand for renting vehicles for short-term use, little is known about the behavior associated with vehicle renting choices. The present study strives to fill this gap by raising the following question: What factors influence consumers' intentions for renting a vehicle for short-term use? We believe people usually rent vehicles for leisure purposes. Vehicles could also be rented to make business trips or as temporary replacements if a vehicle that is owned by the renter is not working. The decision to rent a vehicle for a specific purpose can be thought of as a choice problem that can be modeled based on the socioeconomic characteristics of the renter and the nature of the planned trip.

From a socioeconomic perspective, we postulate that high-income individuals, as well as those working in high-order sectors, ceteris paribus, would lean more towards renting vehicles for business purposes. We also hypothesize that other factors such as gender, age, education, employment, and vehicle ownership could predict the intended purpose for renting a vehicle. When planning a trip that requires renting a vehicle, an individual would normally consider several factors including the cost and size of the vehicle, the destination and the duration of the trip, and the rental pickup location. Therefore, from a user's trip planning perspective, we expect cost to be a significant deterrent in renting

\footnotetext{
* University of Windsor; Civil and Environmental Engineering

† University of Windsor; Civil and Environmental Engineering

Corresponding author email:Hanna.Maoh@uwindsor.ca

‡ University of Windsor; Civil and Environmental Engineering
} 


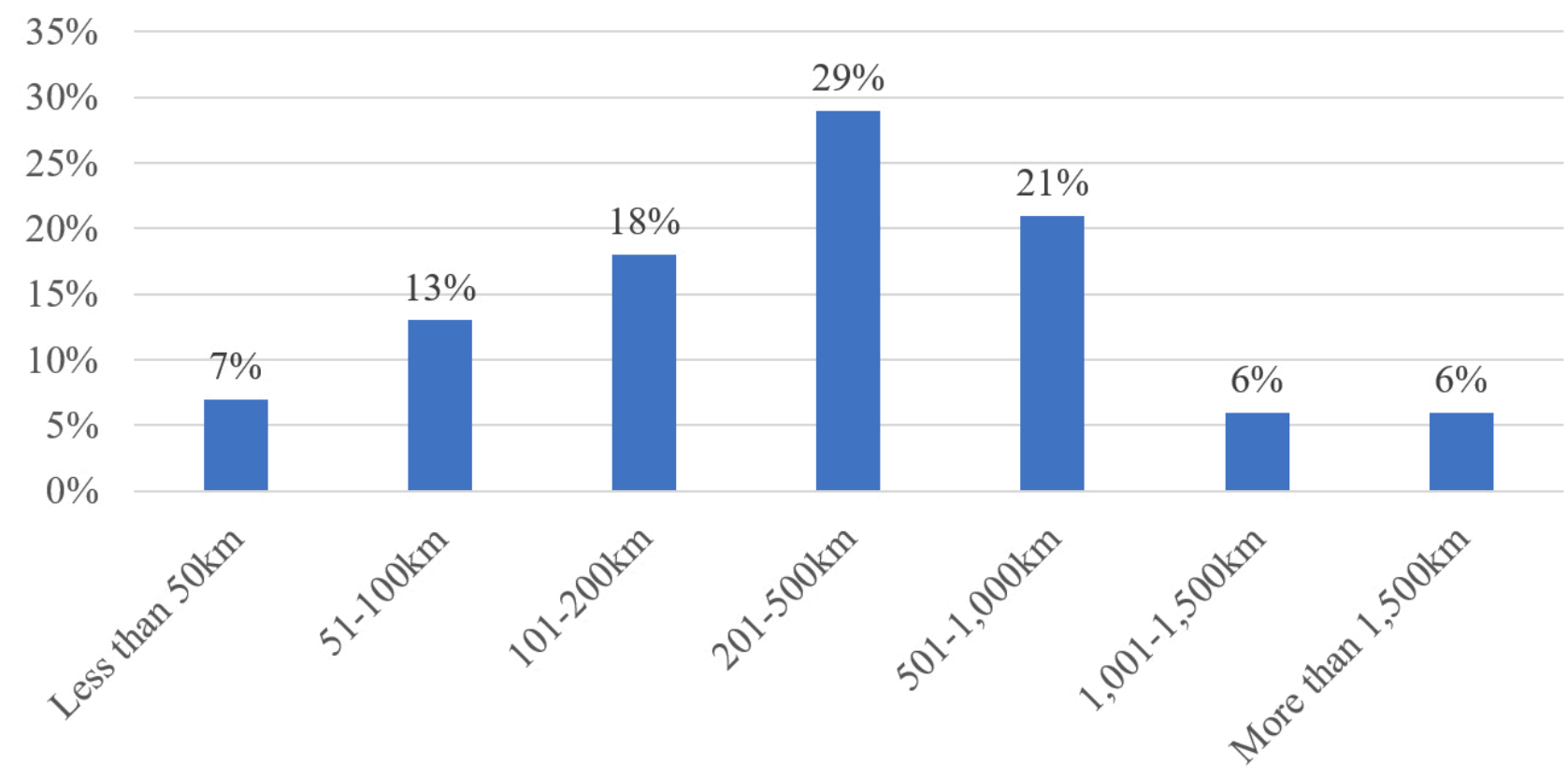

Figure 1: Shares by Range of Distance Traveled $(\mathrm{N}=1,002)$

a vehicle, regardless of the renter's intention. With respect to size, we expect smaller vehicles (i.e., sedans) to be more popular for business purposes. We hypothesize that individuals planning to undertake long trips to get to their destinations would be more likely to rent for business or leisure purposes. Also, individuals contemplating longer rental durations would be more inclined to rent for leisure purposes. On the other hand, individuals aiming to rent for shorter durations (e.g., one to two days) would be more likely to rent for business purposes. Lastly, individuals planning to pick up their vehicles from nearby airports or train stations would be more likely to rent for business or leisure purposes.

\section{METHODS AND DATA}

The dataset utilized here comes from the revealed choice portion of a nationwide online survey deployed in early 2016, targeting approximately 1,000 Canadians (Dimatulac et al. 2018). Nearly 62\% of all respondents indicated that they have rented a vehicle for 'leisure' purposes, while about $34 \%$ acquired a rental vehicle either as a 'temporary replacement' vehicle (18\%) or for 'business' trips (16\%). Meanwhile, the remaining $4 \%$ have 'other' reasons for renting a vehicle, excluding carsharing. Presently, the carsharing service in Canada is minuscule and confined to urban cores only (Movmi 2019). Sociodemographic characteristics of respondents, information on their most recent rental activity shown in Figures 1,2 and 3, and attributes of their rented vehicle are also utilized in this study. 


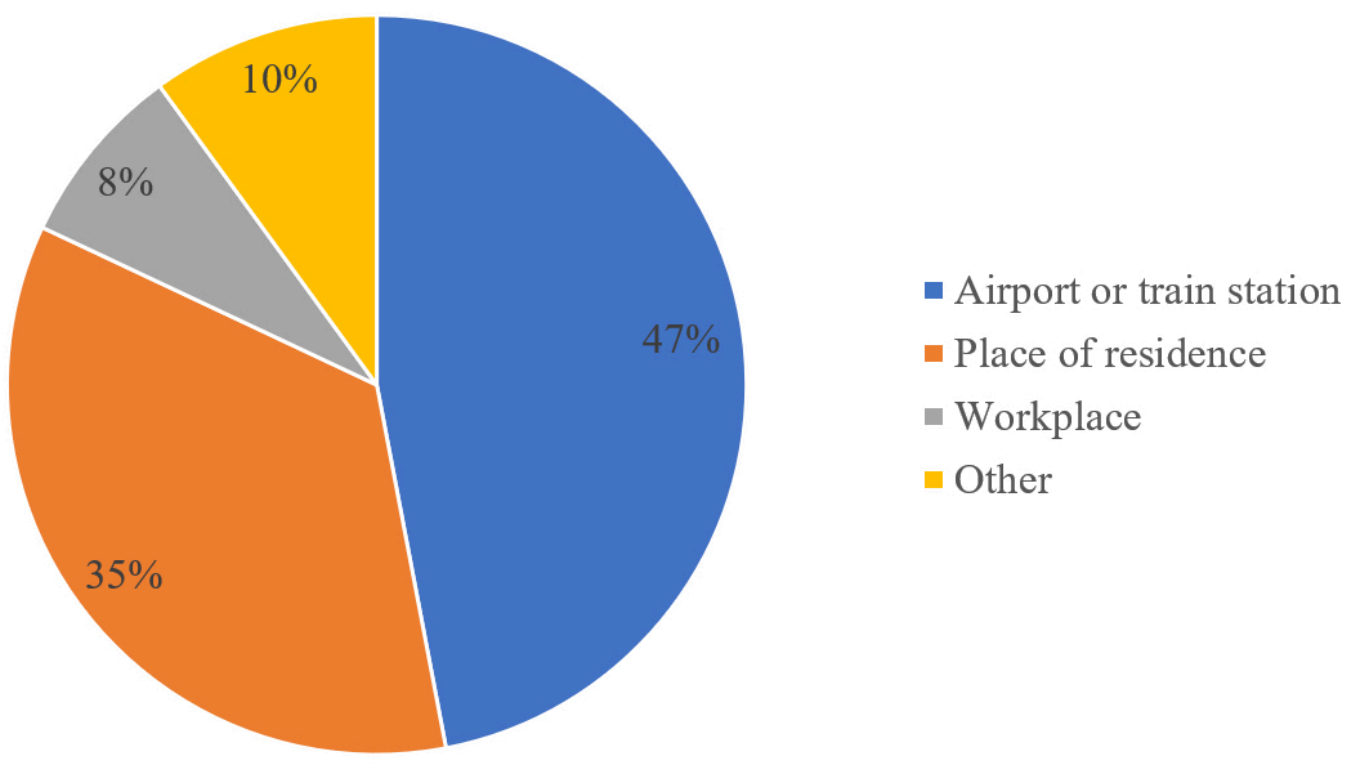

Figure 2: Shares by Rental Vehicle Pickup Location $(\mathrm{N}=1,002)$

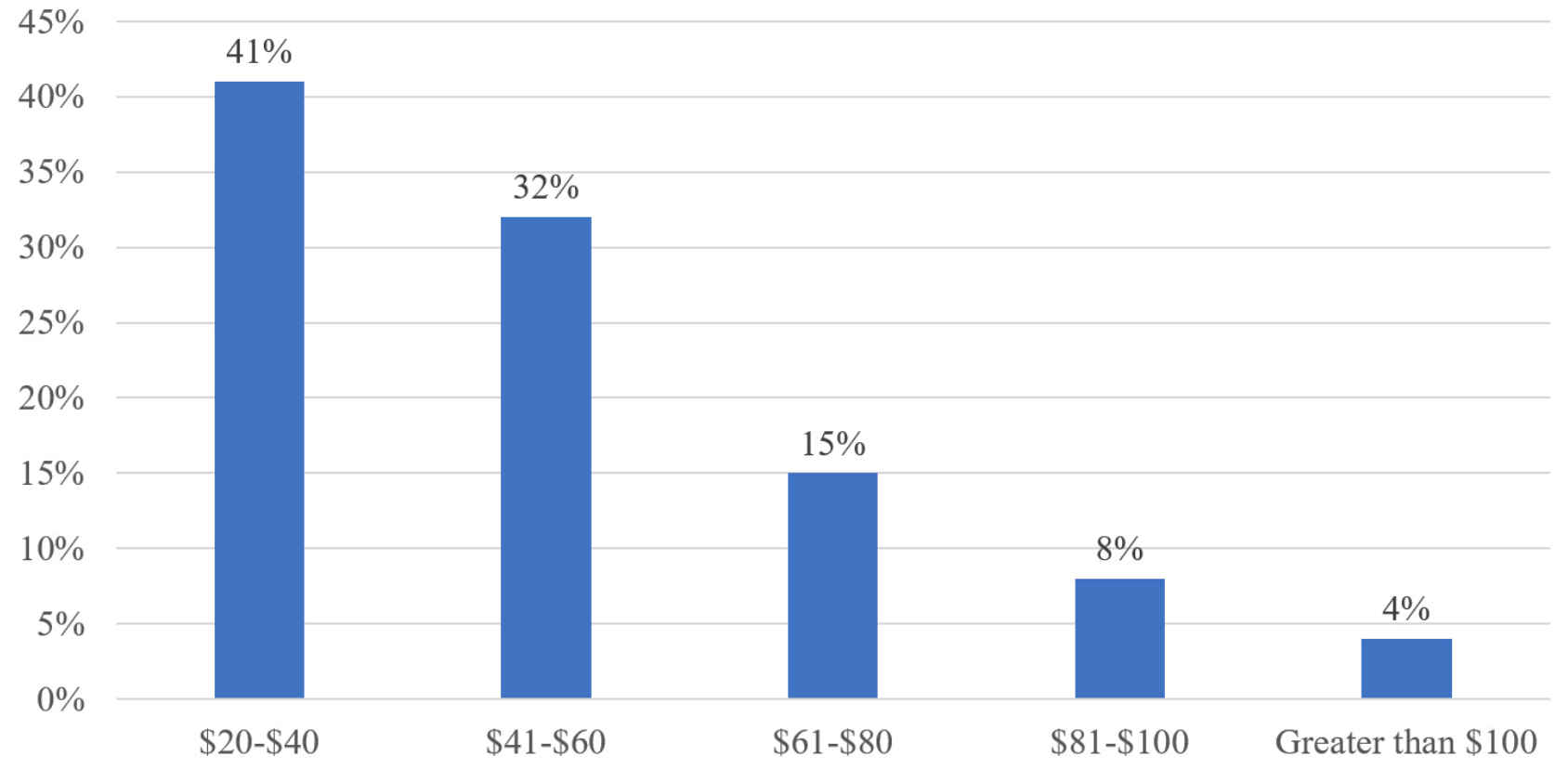

Figure 3: Shares by Daily Rental Cost $(\mathrm{N}=1,002)$

The distribution of surveyed respondents by Canadian province is presented in Table 1. The noticeably low representation of Quebec in the sample is attributable to the fact that the province is predominantly French-speaking, and our survey was administered in the English language only. Table 2 compares key socioeconomic characteristics of the surveyed respondents to 
Table 1: Distribution of Respondents by Canadian Province (Survey vs. Canadian Census)

\begin{tabular}{lll}
\hline Province & Respondents (\%) & 2016 Census (\%) \\
Ontario & 49.7 & 38.4 \\
Quebec & 5.0 & 23.3 \\
British Columbia & 16.2 & 13.3 \\
Alberta & 17.6 & 11.6 \\
Manitoba & 4.2 & 3.6 \\
Saskatchewan & 2.5 & 3.1 \\
Nova Scotia & 2.6 & 2.6 \\
New Brunswick & 0.6 & 2.1 \\
Newfoundland and Labrador & 1.3 & 1.5 \\
Prince Edward Island & 0.4 & 0.4 \\
\end{tabular}

Table 2: General Characteristics of Respondents

\begin{tabular}{|c|c|c|c|}
\hline & & Respondents (\%) & 2016 Census (\%) \\
\hline \multirow[t]{3}{*}{ Gender } & Females & 47.9 & 51.3 \\
\hline & Males & 51.1 & 48.7 \\
\hline & Prefer not to say & 1.0 & - \\
\hline \multirow[t]{4}{*}{ Marital status } & Married/common law & 70.8 & 57.6 \\
\hline & Never married & 18.4 & 28.1 \\
\hline & Widowed/divorced/separated & 8.6 & 14.2 \\
\hline & Prefer not to say & 2.2 & - \\
\hline \multirow[t]{5}{*}{ Education } & High school or lower & 16.3 & 44.7 \\
\hline & College diploma or alike & 30.0 & 32.0 \\
\hline & Bachelor degree & 31.2 & 15.5 \\
\hline & Graduate school & 21.0 & 7.7 \\
\hline & Prefer not to say & 1.6 & - \\
\hline \multirow[t]{6}{*}{ Age group } & 18 to 24 & 5.7 & 14.6 \\
\hline & 25 to 34 & 20.1 & 15.7 \\
\hline & 35 to 44 & 24.2 & 15.5 \\
\hline & 45 to 54 & 20.0 & 17.2 \\
\hline & 55 to 64 & 18.4 & 16.8 \\
\hline & 65 and up & 11.6 & 20.3 \\
\hline \multirow[t]{5}{*}{ Household income } & Less than $\$ 50,000$ & 15.6 & 67.0 \\
\hline & $\$ 50,000-\$ 99,999$ & 37.6 & 24.8 \\
\hline & $\$ 100,000-\$ 149,999$ & 20.5 & 5.4 \\
\hline & Greater than $\$ 150,000$ & 13.3 & 2.8 \\
\hline & Prefer not to say & 13.0 & - \\
\hline
\end{tabular}

those that are reported in the 2016 Census. Here, the significant differences noted in the shares of some of the characteristics are expected as our sample only targeted individuals who rented vehicles within the last 12 months preceding the launch of the survey. 
A multinomial logit (MNL) model is estimated using NLOGIT 5.0 (Greene 2007) to examine our postulated hypotheses about the factors affecting individual's purpose for renting a passenger vehicle. The choice set in the MNL model consists of the following four alternatives: (1) business purpose; (2) leisure purpose; (3) temporary replacement; and (4) other purpose.

\section{FINDINGS}

The findings reported in Table 3 support our postulated hypotheses. People are highly likely to rent vehicles for leisure purposes. As postulated, high income individuals, as well as those working in the business and management sectors, are inclined to rent vehicles for business purposes. Likewise, people considering loyalty programs and discounts offered by vehicle rental companies are equally inclined to rent either for business or leisure purposes. The probability of renting vehicles for temporary replacement is higher among people owning vehicles. The same could be said about females, in general. However, females with high income are more likely to rent vehicles for leisure purposes. The propensity of renting vehicles for business and leisure purposes is higher for highly educated individuals. Similar results can be reported for young single adults. By comparison, seniors are more likely to rent for other purposes, all things being equal.

The postulated hypotheses pertaining to renters' trip planning are, to a large extent, supported by the estimated model. The impact of rental cost is partially corroborated as the model indicates that individuals planning to spend less (i.e., \$20-\$40) are more likely to rent vehicles for leisure and temporary replacement purposes only. According to the model, people planning to rent smaller vehicles (i.e., sedans) are more likely to use them for business, leisure, or temporary replacement, although the probability of renting this class of vehicles is found to be the highest for temporary replacement purposes. On the other hand, individuals planning to rent larger vehicles (i.e., SUVs) are more likely to use them for leisure and temporary replacement, although the probability is higher in the case of the latter. Individuals planning long distance trips (i.e., more than $200 \mathrm{~km}$ ) are more likely to rent for leisure purposes. However, the same effect is not observed in the case of renting for business purposes. Individuals planning to pick up their rental vehicles from a location near an airport or a train station are more likely to rent for business or leisure purposes. It can be further stated that travel plans for longer durations increase the chance of renting for leisure or temporary replacement purposes. By comparison, individuals planning to rent for a short duration of one to two days are more prone to use the vehicle for business purposes. 
Table 3: Parameter Estimates of the MNL Model

\begin{tabular}{|c|c|c|c|c|}
\hline \multirow[t]{2}{*}{ Variable Description ${ }^{a}$} & \multicolumn{4}{|c|}{ Utilities } \\
\hline & Business & Leisure & Temporary Replacement & Other \\
\hline Alternative-specific constant & & $1.094^{* * *}$ & & \\
\hline \multicolumn{5}{|l|}{ Sociodemographic characteristics } \\
\hline High income (more than $\$ 75,000$ ) & $0.664^{* * *}$ & & & \\
\hline Full time worker $\times$ Business or management sector & $0.837^{* * *}$ & & & \\
\hline Female & & & $0.954^{* * *}$ & \\
\hline Female $\times$ High income (more than $\$ 75,000$ ) & & $0.741^{* * *}$ & & \\
\hline Young adults (between 18 and 44 years) $\times$ Single & $0.781^{* *}$ & $1.028^{* * *}$ & & \\
\hline Seniors ( 65 years and above) & & & & $1.100^{* *}$ \\
\hline Highly educated (with at least bachelor's degree) & $0.637^{* * *}$ & $0.405^{* *}$ & & \\
\hline Owns a vehicle & & & $0.752^{* *}$ & \\
\hline Considers loyalty program and discounts when renting & $0.827^{* * *}$ & $0.827^{* * *}$ & & \\
\hline \multicolumn{5}{|l|}{ Rental vehicle plan } \\
\hline Low rental cost (i.e., $\$ 20$ to $\$ 40$ per day) & & $0.691^{* * *}$ & $1.022^{* * *}$ & \\
\hline Small vehicle (i.e., sedan) & $0.715^{* *}$ & $0.715^{* *}$ & $0.905^{* *}$ & \\
\hline Large vehicle (i.e., SUV) & & $0.781^{* * *}$ & $1.449^{* * *}$ & \\
\hline Short travel distance (i.e., less than 50km) & $-1.110^{* * *}$ & $-1.110^{* * *}$ & & \\
\hline Long travel distance (i.e., more than $200 \mathrm{~km}$ ) & & $0.609^{* * *}$ & & \\
\hline Total number of days vehicle is rented & & $0.057^{* *}$ & $0.057^{* *}$ & \\
\hline Rented only for one day & & & & $1.842^{* * *}$ \\
\hline Rented for one to two days & $0.934^{* * *}$ & & & \\
\hline Acquired from nearby airport or train station & $3.276^{* * *}$ & $3.276^{* * *}$ & & $2.558^{* * *}$ \\
\hline Acquired from nearby place of residence & & $0.632^{* * *}$ & $0.847^{* * *}$ & $1.084^{* * *}$ \\
\hline Number of observations & & & 1,002 & \\
\hline Log-likelihood (0) & & & $-1,389.067$ & \\
\hline Log-likelihood (constant) & & & $-1,042.848$ & \\
\hline Log-likelihood (beta) & & & -790.040 & \\
\hline McFadden Pseudo $R^{2}$ & & & 0.242 & \\
\hline ote: ${ }^{* * *}$ within $1 \%$ significance; ${ }^{* *}$ within $5 \%$ significance & & & & \\
\hline
\end{tabular}

\section{ACKNOWLEDGMENTS}

This research was supported by the Social Sciences and Humanities Research Council (SSHRC) of Canada through Grant No: 886-2013-0001. The research was also enabled by a Canada Foundation of Innovation (CFI) Infrastructure Grant.

The authors dedicate this work to the memory of Professor Pavlos Kanaroglou (1948-2016). 


\section{REFERENCES}

Canadian Automotive Fleet. 2019. “Annual Canadian Automotive Fleet Fact Book.” 2019. https://www.fleetbusiness.com/fact-book.

Dimatulac, Terence, Hanna Maoh, Shakil Khan, and Mark Ferguson. 2018. "Modeling the Demand for Electric Mobility in the Canadian Rental Vehicle Market." Transportation Research Part D: Transport and Environment 65 (December): 138-50. https://doi.org/10.1016/ j.trd.2018.08.002.

Greene, W.H. 2007. NLOGIT Version 4.0 Reference Guide. New York: Econometric Software Inc.

Movmi. 2019. "Shared Mobility by Region: Canada." March 12, 2019. http://movmi.net/sharedmobility-canada/. 